\title{
PERGESERAN TRADISI KHITAN ANAK PEREMPUAN DI KUDUS JAWA TENGAH
}

\author{
Moh Rosyid \\ Institut Agama Islam Negeri (IAIN) Kudus \\ Jl. Conge Ngembalrejo Bae Kudus Jawa Tengah PO BOX 51 \\ Email: mrosyid72@yahoo.co.id
}

Abstract: This paper aims to describe the shift in the circumcision tradition of girls in Kudus, Central Java. The focus of this shift discussion was mainly on the shift of circumcision done by Dukun Bayi (Traditional Midwife) to that done by a professional midwife, and the prevailing cultural shift is also illustrated. The data were collected through interviews with mothers of the circumcised girls through random sampling. This research is categorized as a case study. The collected data were analyzed using a qualitative descriptive approach. The results of the study revealed that the tradition of girl circumcision is a result of following a tradition that has been done for ages, the understanding of figh experts plays a role in the circumcision of girls. As the village midwife is serving childbirth, the circumcision that was initially done by a dukun now is done by professional midwives. The dukun played as a massage therapist to mothers with old pregnancy, also to the postpartum mothers and their babies. The knowledge that girls circumcision needs to be done by medical staff (midwives) will be more optimal if the village government facilitates the role of village midwives in Kudus.

Keywords: girls, circumcision, shifting tradition, and Kudus.

Abstrak: Tulisan ini bertujuan untuk mendeskripsikan pergeseran tradisi khitan anak perempuan di Kudus, Jawa Tengah. Faktor utama perubahan tersebut adalah munculnya pengkhitan bidan desa-yang sebelumnya dilakukan oleh dukun bayi-dan menggambarkan perubahan budayanya. Data diperoleh melalui wawancara dengan ibu dari anak perempuan yang dikhitan secara random sampling. Riset ini kategori studi kasus, data yang terkumpul dianalisis dengan pendekatan deskriptif kualitatif. Hasil penelitian mengungkapkan bahwa tertradisinya mengkhitan akibat mengikuti tradisi, yakni pemahaman ahli fikih tentang khitan pada anak perempuan. Seiring adanya bidan desa yang melayani persalinan warga, 
maka pengkhitan yang semula dukun bayi ada yang dialihkan pada bidan desa. Dukun bayi diperankan sebagai tukang pijet pada ibu yang usia kandungannya menua dan memijat ibu pascamelahirkan beserta bayinya. $\mathrm{Hal}$ yang perlu dipahami agar mengkhitan anak perempuan dilakukan oleh tenaga medis (bidan) makin optimal bila peran bidan desa difasilitasi oleh pemerintah desa di Kudus.

K ata Kunci: anak perempuan, khitan, pergeseran tradisi, dan Kudus.

\section{A. PENDAHULUAN}

Praktik khitan, bagian yang dikhitan pada anak laki-laki adalah tepi bulat yang menutupi hasyafah (ujung kemaluan) atau kulit penutup kepala dzakar (praeputium), sedangkan pada anak perempuan adalah kulit yang berbentuk jengger ayam jantan di bagian atas farji (klitoris). Hikmah khitan pada lelaki jelas yakni untuk memelihara kebersihan, menghindari dari berbagai jenis penyakit berbahaya seperti kanker dan beser (tingginya frekuensi kencing) yang virusnya bersarang di kulup (kepala penis) sebelum dikhitan, dan dapat mengurangi praktik masturbasi atau onani bagi orang yang balig/dewasa. Selain itu, agar ujung penis tidak tertutup oleh smegma (faktor yang diduga menjadi predisposisi/memudahkan timbulnya kanker penis laki-laki dan kanker leher rahim pada perempuan jika berhubungan seks dengan laki-laki yang belum berkhitan), menghilangkan penimbun kotoran yang dihasilkan dari kelenjar skresi di penis.

L ebih jelasnya, menurut dokter spesialis bedah/urologi RSUP Dr. K ariadi Semarang, dr. A rdy Santosa,Sp.U dampak tidak terjaganya kebersihan organ tubuh, termasuk organ/alat vital lelaki berdampak pada penyakit kelamin yang disebut balanitis yakni infeksi pada batang penis. Bila tidak dilakukan pendekatan medis berpeluang menjalar hingga ke saluran kencing. $B$ alanitis biasanya disertai fibrosis yakni lengketnya kulup (kulit) penis karena tidak disunat. Bila kulup penis juga terinfeksi maka menimbulkan balanoposthitis. Penyakit ini terobati dengan dikhitan. Gejala penyakit balanoposthitis berupa peradangan kulit (dermatitis), erosi merah-merah kecil pada bagian glans (kepala kelamin) dan kulup, merah pada seluruh penis, berbau, nyeri, dan gatal. Bila disertai fibrosis (bercak putih) penyakit akan menyebar ke saluran kencing berdampak penyempitan saluran kencing (striktur ureta). Dapat pula diakibatkan infeksi jamur candida albicans sehingga kepala kelamin berlumuran 
jamur karena rentan tertular akibat hubungan seks dari vagina yang mengidap keputihan jamur. Dampaknya, kesulitan pipis dan menyumbat pembuangan air seni. D ampak lanjutannya, menurut dr. A rdy, berbahaya pada ginjal. B agi yang telah khitan pun, penyakit balanitis tidak bebas begitu saja karena kebersihan pada alat kelamin lelaki sebagai solusi penangkal dini. Jenis balanitis yakni (1) kepala penis memerah karena kulup ukurannya panjang (candida albicans balanitis), (2) akibat gesekan pada celana dalam pria atau sabun sehingga memerah (balantis dangkal akut), (3) pasangan menderita penyakit trichomonas yang menular (trichomonas balanitis), dan (4) kulup penis bernanah karena akut (balanitis bernanah) (Suara M erdeka, $11 \mathrm{M}$ ei 2014).

M engkhitan anak lelaki dipahami sebagai kewajiban, tetapi menghitan anak perempuan menjadi polemik akibat dasar hukumnya yang diperdebatkan oleh para ahli fikih didukung data ekses negatifnya dari pegiat jender. A kan tetapi, praktik mengkhitan anak perempuan telah mentradisi, khususnya di K udus J awa Tengah. Pilihan lokus ini dengan dalih, pertama, K udus dipandang oleh publik sebagai basis Islam, sebagai pusat islamisasi di Jawa (baca: Indonesia selain di A ceh), sehingga muncul berbagai spekulasi bahwa kekentalan beragama Islam (mungkin) lebih kental jika dibandingkan dengan 'daratan' Iainnya dalam konteks I ndonesia. K edua, aroma Islam J awa (melaksanakan ajaran I slam dan tradisi J awa) memberi andil untuk ditelaah atas pemahaman Islam murni, khususnya kaitannya dengan pemahaman masyarakat I slam K udus atas khitan perempuan. K etiga, stratifikasi sosial masyarakat J awa yang perlu ditelaah secara ekstra. B atasan wilayah Pantura dalam naskah ini secara geografis dibatasi hanya di wilayah Kabupaten K udus, meski tidak memiliki pantai, nonpesisir, hanya karena dilalui jalan D aendels, yakni jalan yang menyusuri wilayah Pantai J awa Tengah, mulai dari B rebes hingga R embang J awa Tengah. K eempat, masyarakat Islam Jawa diidentikkan dengan komunitas santri dan abangan yang masi helaksanakan khitan pada anak perempuan meski mengalami perubahan.

M enurut Waharjani, khitan dilaksanakan kalangan $\mathrm{K}$ raton Jawa pada anak lelakinya disebut supit atau tetak dan anak perempuannya disebut tetes atau kafad. K hitan di K raton Y ogyakarta berdasarkan ajaran Islam dan tidak melepaskan tradisi penganut I slam kejawen atau agama Jawi (Waharjani, 2000: 196). Riset yang dilakukan R osyid di sebagian wilayah K abupaten Demak bahwa yang melatarbelakangi mengkhitan anak perempuan karena 
anggapannya bahwa perempuan tidak sah ibadah hajinya bila tidak dikhitan. $\mathrm{K}$ hitan dipandang sebagai upaya mengislamkan (diislamke). Padahal pandangan warga tersebut sangat Iemah. A dapun di K udus beranggapan bahwa mengkhitan anak perempuan melestarikan tradisi leluhur yang berdasarkan ajaran Islam (Rosyid, 2008:80-81). Wijayati menyoroti khitan perempuan dari aspek akar geneologis pensyariatan bahwa praktiknya ada di lebih dari 20 negara khususnya muslim bermazhab Syafi' i. A da dua perspektif fuqaha (1) hukumnya wajib karena berkaitan dengan khitan lelaki, sebagaimana dalil ushul figh syar'un man qablana (disyariatkan sebagaimana generasi pendahulu) diperkuat penafsiran dalam al-Quran Q .s al-B aqarah:124 dan an$\mathrm{N}$ ahl:123. Pelaksanaannya mendapat reaksi publik karena dinilai dapat merusak hak reproduksi kaum perempuan dan merampas kesehatan serta kepuasan seksual. Praktik khitan perempuan di B enua A frika seperti K amerun, Sierra L eone, G hana, M auritania, Chad, M esir U tara, K enya, Tanzania, B oswana, M ali, Sudan, Somalia, Ethiopia, dan Nigeria. Di A merika L atin seperti B rasil, M eksiko bagian timur, dan Peru. Di Eropa sebagaimana Inggris, Perancis, B elanda, Sw edia ol eh kalangan imigran (Wijayati, 2009:6667). A inol menganal isa hadis Sunan A bu D awud N omor Indeks 5271 tentang K hitan. Hadis bersanad pada A bu Dawud, A bdul Wahab bin A bdul Rahim, dan Sulaiman bin A bdul Rahman, $M$ arwan bin M uawiyah, M uhammad bin Hasan, A bdul M alik bin U mair, dan U mmi 'A tiyah al-A nshari. Semua periwayat tersebut sahih kecuali M uhammad bin Hasan karena tidak diketahui sifat adil dan dlabitnya sebagai perawi bahkan ada yang menilai ia sebagai perawi majhul sehingga hadis indeks 5271 kategori dloif (A inol, 2013:370). K ondisi polemik itulah maka menelaah praktik khitan pada anak perempuan yang lokusnya di K udus berada di Pantura Timur Jawa Tengah memiliki aspek kebaruan dan menyimpan satu hal yang dinamis.

Riset ini dilakukan penulis pada tahun 2019, data diperoleh dengan wawancara pada pihak yang melakukan khitan secara random sampling Setelah data terkumpul data direduksi sesuai kebutuhan kemudian disajikan dalam naskah. Data dianalisis dengan pendekatan deskriptif kualitatif.

\section{B. DISYARIATKANNYA KHITAN}

A rti kata khitan yang sebenarnya adalah nama bagian tubuh berupa kulit yang tersisa setelah dipotong, sedangkan arti khitan secara syar'i dari kata alkhitan isim masdar dari kata khatana berarti memotong. Dari segi bahasa, kata 
'khitan' berasal dari kata kha', ta', dan nun yang membentuk dua kata yang berbeda (1) khatn artinya jalinan persaudaraan melalui perkawinan (bahasa J awa: besanan), (2) khatn adalah istilah bahasa A rab yang berarti 'khitan' bagi laki-laki, sedangkan istilah bagi perempuan adalah khafdh. A da juga yang berpendapat, istilah khatn berlaku untuk laki-laki atau pun perempuan. $M$ akna asli kata 'khitan' dalam bahasa A rab adalah bagian yang dipotong dari kemaluan laki-laki atau perempuan. A da pula istilah al-uqluf adalah sebutan bagi orang yang belum dikhitan. $\mathrm{K}$ hitan adalah memotong kulit bagian kepala kelamin laki-laki hukumnya wajib dengan dalih termasuk di antara syiar Islam. K ata lain dari khitan adalah i'dzar (bagi laki-laki) dan khafadz (bagi perempuan). Dalam konteks tradisi lisan di A rab, bangsa A rab beranggapan bahwa apabila seseorang dilahirkan pada malam bulan purnama, maka kulup sudah dalam keadaan terpotong atau sudah dikhitan.

B erdasarkan pesan al-B aqarah: 124, "K etika Ibrahim di uji Tuhannya dengan beberapa kalimat (perintah dan Iarangan) Ialu menunaikannya". A yat tersebut dapat ditafsiri bahwa Allah menguji $\mathrm{N}$ abi Ibrahim dengan bersuci pada lima hal yakni di kepala (memotong kumis, berkumur, memasukkan air ke liang hidung (istinsyaq), bersiwak, dan menyisir rambut) dan lima hal di jasad (memotong kuku, memotong bulu kemaluan, mencabut bulu ketiak, membersihkan sisa buang air besar, dan air kecil). Hadis yang diriwayatkan Shahih Bukhori dan M uslim bahwa Nabi Ibrahim berkhitan dalam usia 80 tahun menggunakan kapak. Dalam A n-N ahl:123 disebutkan bahwa "Kami wahyukan kepadamu (M uhammad) ikutilah agama Ibrahim". Dengan ayat ini sehingga disyariatkannya khitan oleh umat $\mathrm{N}$ abi M uhammad karena mengikuti syariat Nabi Ibrahim.

Secara medis, khitan (sirkumsisi) bagi laki-laki diharapkan dapat meningkatkan kesehatan karena di bawah/dalam kulup penis sering terbentuk zat berwarna putih yang disebut smegmal. Jika tidak dibersihkan secara teratur menimbulkan bau dan peradangan, muncul pula kanker yang menyerang penis (dzakar). I mbasnya menularkan kanker rahim pada perempuan jika bersenggama (koitus) (M arzuki, 2001:41). B erdasarkan penelitian J ames Kahn dari University of Calivornia, San Francisco, studi yang dilakukan di Kota O range Farm, J ohannesburg, dari 1000 pria yang diteliti, dapat mencegah 300 pria dari HIV 20 tahun mendatang atau khitan dapat mencegah penularan HIV hingga 60 persen. Dengan kalkulasi, pemerintah dapat menghemat dana perawatan penderita HIV /AIDS hingga USD 2,4 juta atau Rp 21,8 miliar. 
Pesan peneliti agar tindakan preventif lain seperti penggunaan kondom tetap mendapatkan perhatian (J awa Pos, 27 D esember 2006). K hitan/sirkumsisi (pada lelaki) menurut Djauzi didefinisikan prosedur (tertua bidang bedah medis) yakni membuang bagian ujung dari kulit penis yang menutupi glans penis. Teknik mengkhitan dengan (1) cara standar, memotong dengan pisau atau gunting bedah, pisau listrik (electrocauter) atau laser, (2) dengan klem atau semacam cincin untuk menjepit kulit penis, membiarkannya menjadi jaringan yang mati (nekrotik) yang akhirnya terlepas. Perlu waktu 3-5 hari dan kulit penis menjadi terlepas (2016:25).

\section{HUKUM KHITAN MENURUT EMPAT IMAM MADZHAB}

Hukum diberlakukannya khitan ditujukan kepada tiga jenis kelamin manusia yakni untuk laki-laki, perempuan, dan banci/waria (khuntsa). A dapun pendapat Imam M adzhab tentang khitan diulas oleh A I-M arshafi (1996:13-35).

Pertama, M adzhab Hanafi. Pengikut Imam A bu Hanifah berpendapat bahwa khitan hukumnya sunah untuk laki-laki dengan memotong semua kulit yang menutup khasyafah farji laki-laki. K hitan bagi perempuan (female genital mutilation) komponen yang dipotong terdiri dua bagian (1) sebagai simbol kegadisan dan (2) klitoris (jengger jago) yang berfungsi sebagai pusat kenikmatan perempuan jika berhubungan seks. A dapun anggota/organ yang dipotong adalah sebagian kecil klitorisnya. Waktu mengkhitan anak lelaki ada yang berpendapat setelah usia baligh atau usia 9/10 tahun atau ketika anak mampu menahan rasa sakit dikhitan. Diwajibkannya khitan karena dianggap sebagai bentuk syiar Islam, seperti halnya adzan. K hitan hukumnya sunah untuk laki-laki tetapi kalau meninggalkannya dia harus dipaksa. K hitan untuk perempuan dipandang baik ada juga yang memandang sunah, adapun khitan untuk banci adalah sunah.

Kedua, M adzhab M aliki. Para pengikut Imam M aliki berpandangan bahwa khitan untuk lelaki dan perempuan hukumnya sunah, bagi banci yang belum diketahui jenis kelaminnya secara pasti tidak perlu dikhitan, yang dipotong adalah kulit penghalang khasyafah, untuk perempuan adalah klitorisnya (sedikit saja). Waktu mengkhitan ketika usia bayi atau setelah tanggalnya gigi susuan. M enurut I mam Malik di dalam buku al- $M$ untaqa' Syarh al-M uwattha', Ibnu A bdil Barr (di dalam buku al-K afi) dan Syekh 'A liasi dalam buku M anhul J alil) pendapat tersebut diperkuat ol eh M adzhab 
Imam M alik Syekh K halil, beliau menghukumi khitan dengan sunnah muakkadah, tetapi Sahnun mengatakan, khitan wajib untuk laki-laki, sedangkan dalam kitab at-Talqin dikatakan bahwa hukum khitan adalah sunah (tidak diharuskan). I bnu Habib meri wayatkan dari I mam M alik bahwa barang siapa tidak berkhitan tanpa suatu alasan dan sebab maka ia tidak berhak menjadi imam dalam salat dan persaksiannya tidak berlaku. I mam al-B aji berkata," J ika orang tidak berkepribadian baik, maka persaksiannya ditolak. D emikian pula seseorang yang tidak mau berkhitan tanpa suatu alasan, persaksiannya ditolak karena ia tidak berkepribadian baik.

K etiga, M adzhab Syafi' i. Sebagian besar ulama ahli fiqih pengikut I mam Syafi'i berpendapat bahwa khitan untuk laki-laki, perempuan, dan untuk banci yang belum jelas jenis kelaminnya hukumnya wajib. Organ yang dipotong adalah kulit yang menutup khasyafahlaki-laki dan untuk perempuan klitorisnya (sedikit saja) sedangkan waktu mengkhitan adalah wajib setelah usia anak baligh dan sunah sebelum usia akil baligh.

K eempat, M adzhab H ambali. Para ulama madzhab Hambali berpendapat bahwa hukum khitan wajib untuk laki-laki, sedangkan untuk perempuan ada yang berpendapat wajib ada juga yang menyatakan tidak wajib (hukumnya baik), adapun untuk banci lebih utama dikhitan kedua kelaminnya. A dapun pemotongannya adalah sampai terlihat khasyafahnya laki-laki, sedangkan untuk perempuan sedikit pada klitorisnya. A dapun waktu mengkhitannya wajib jika usia akil baligh dan ketika masih kecil diutamakan (AI-M arshafi, 1996:13-53).

M engulas khitan berdasarkan analisis Waharjani dengan tinjauan antropologis-sosiologis disimpulkan bahwa khitan anak laki-laki dan perempuan telah menjadi budaya global. Di J awa, khitan menjadi tradisi yang bersumber dari Islam (2000:196). B erdasarkan penelitian J ames K ahn dari University of Calivornia, San Francisco, studi yang dilakukan di K ota O range Farm, J ohannesburg, dari 1000 pria yang diteliti, dapat mencegah 300 pria dari HIV 20 tahun mendatang atau khitan dapat mencegah penularan HIV hingga 60 persen. Dengan kalkulasi, pemerintah dapat menghemat dana perawatan penderita HIV /A IDS hingga USD 2,4 juta atau R p 21,8 miliar. Pesan peneliti agar tindakan preventif lain seperti penggunaan kondom tetap mendapatkan perhatian (Jawa Pos, 27 Desember 2006).

M engkhitan perempuan terjadi polemik (sebagaimana dalam konferensi kependudukan di K airo yang diselenggarakan PB B tahun 1994). M engkhitan 
perempuan tidak didukung oleh teks otentik Islam, hanya tradisi pra-Islam. Syekh A I-A zhar Gad A I-Haq menyatakan bahwa khitan bagi perempuan adalah tradisi islami. A nalisis Lily Zakiyah M unir bahwa disunahkannya perempuan dikhitan berdasarkan hadis yang diriwayatkan oleh A bu Dawud dari U mi A tiyah al-A nsariyah bahwa di Madinah biasanya perempuan disunat. $\mathrm{N}$ abi bersabda jangan dipotong terlalu banyak karena lebih baik bagi perempuan dan lebih diinginkan suami. Hadis tersebut dianggap lemah oleh A bu Dawud sendiri dan diklasifikasikan sebagai hadis mursal yaitu hadis yang kehilangan mata rantai riwayat karena tidak ditemukan di antara para sahabat Nabi. M enurut Sayyid Sabiq, hadis tentang khitan perempuan berkualifikasi dlaif (lemah kualitasnya) (2005:74). Tujuan sunat bagi perempuan, menurut Lily adalah untuk mengurangi atau menghilangkan sensitivitas jaringan di daerah genital terutama klitoris guna mengurangi gairah seks perempuan, menjaga keperawanan sebelum menikah dan agar tetap setia dalam pernikahan. Dampak yang diaki batkannya adalah rasa sakit, perdarahan, shock, tertahannya urine, l uka pada jaringan sekitar alat kelamin. Dari aspek psikologis muncul dampak seumur hidup berupa depresi, ketegangan, dan rasa rendah diri (Kompas, 16 Oktober 2006).

Pengamatan seorang bidan yang menangani persalinan, Gunadi, berdomisili di Bandung, telah 37 tahun sebagai bidan, menulis pada harian Kompas, ia meli hat luka yang ada dalam dinding vagina berdampak merusak selaput dara (hymen) berbahaya dari sisi medis, oleh penderita diakibatkan oleh khitan (Kompas, 24 M aret 2003). A nalisis Lies M arcoes Natsir bahwa dikhitannya perempuan dengan tujuan mengendalikan nafsu seks dipertanyakan validitasnya secara medis (Kompas, 17 Februari 2003). Hal ini dapat dibedakan dengan khitan bagi laki-laki yang dipotong kul it penis (preputium) yang berposisi di kepala penis (glans) jika tidak dipotong akan berpeluang menimbulkan penyakit karena tersumbatnya saluran air seni (ureter).

\section{PERGESERAN BUDAYA KHITAN ANAK PEREM- PUAN}

A da tiga isu dunia yang menjadi obsesi global sehingga mendapat porsi kajian pokok yakni terciptanya demokrasi, ramah lingkungan, dan kesetaraan jender. A pabila satu atau ketiganya terjadi hal yang tidak baik dan benar menurut standar umum maka akan direspon negatif ol eh publik global. Jender mendapatkan ekstrakajian karena (selama ini) pemahaman publik atas jender 
keluar dari norma seperti perempuan/wanita diposisikan termarjinal oleh sistem politik, ekonomi, budaya, kombinasi ketiga sistem dan sistem lainnya. J ika marjinalisasi berkelanjutan, dikhawatirkan terus terjadi diskriminasi atas wanita oleh individu, kelompok, bahkan negara. Tidak bedanya pemahaman publik atas perempuan/wanita khususnya perihal khitan yang rentan terjadi diskriminasi menjadi polemik. Budaya yang dilakukan oleh warga di Kudus J awa Tengah terkait khitan pada anak perempuan mengalami perubahan mendasar.

\section{Mengundang Tamu dan Seni Pertunjukan Tradisional}

M engundang tamu bila memiliki hajat (duwe gawe) merupakan kelaziman karena dijadikan media bersilaturahim antara tuan rumah dengan tetangga, saudara yang dekat lokasi (tetangga) ataupun yang jauh lokasi rumahnya (berbeda wilayah). K awasan/wilayah Gunung M uria K udus pada tahun 1970 s.d 1990-an tuan rumah yang memiliki hajatan (menikahkan anak laki-laki atau permpuan, menghitankan anak laki-laki atau perempuan) mengundang warga tetangga, saudara selingkungan dan saudara dari desa lain diberi undangan untuk menghadiri acara khitanan anak perempuan. Bahkan ada yang mengundang kesenian tradisional untuk menghibur tamu undangan. A nak perempuan dikhitan pada usia variatif, ada yang pada usia 0 bulan, 7 hari, 36 hari, 40 hari, dengan sebutan disunat atau dikhitan. Tujuan mengkhitan agar terhindar dari penyakit kelamin, bila berkeluarga lebih cepat mencapai orgasme dalam hubungan intim, menyucikan organ vital, dan meneruskan tradisi yang tertradisi. Dasar hukum melaksanakan khitan bersandar pada hadis riwayat al K hatib dalam Tarikh 5.327 yang dinilai sahih oleh Syaikh A Ibani dalam K itab A sh Sahihah. Teknis mengkhitannya secara simbolik yakni dikerik/digores sedikit, dipotong/dilukai dengan silet pada klitorisnya. Dampaknya, ada yang tidak berefek/tidak berpengaruh secara fisik, ada yang nampak sakit dibuktikan dengan bayi menangis. U pah yang diberikan pada pengkhitan ada yang Rp 50 ribu, ada juga Rp 100 bahkan Rp 150 ribu (karena tidak ada standar baku) hanya berdasarkan standar pribadi pemberi upah.

A kibat pola pikir warga yang berubah imbas pemahamannya bahwa di wilayah lain (mengkhitan anak perempuan) tidak mengadakan acara mengundang tamu yang membawa sumbangan uang bagi tamu lelaki dan membawa sembako bagi tamu perempuan. Kompensasinya tamu diberi hidangan 
makanan dan seporsi makanan siap saji ol eh tuan rumah untuk di bawa pulang (berkatan). Perkembangan selanjutnya, khitan pada anak lelaki diutamakan mengundang tamu sedangkan mengkhitan anak perempuan tanpa mengundang kelompok kesenian tradisional karena tidak lagi mengundang tamu. Faktor lain karena keluarga bila dalam satu tahun telah melakukan acara hajatan (menikahkan atau mengkhitankan anak lelaki) dengan mengundang tamu, merasa tidak bijaksana bila mengundang tamu pada acara serupa pada tahun yang sama. M asa mengkhitan pun disertakan bersamaan dengan pemberian nama (acara tasmiyahan) tatkala anak perempuan berusia 36 hari (selapan). B agi keluarga yang mampu secara ekonomi, acara ini juga dilaksanakan akikahan yakni menyembelih seekor kambing yang dimasak dan daging yang termasak untuk acara slametan (walimatut tasmiyah). K ondisi ini, meski tidak kondangan, buwoh yakni membawa uang sebagai ungkapan suka diundang bagi lelaki dan perempuan, tetapi bagi iu-ibu yang bertamu membawa sembako.

Perubahan lainnya adalah selama rentang waktu yang lama, pihak yang mengkhitan adalah dukun bayi yang juga memijat ibu sejak mengandung (usia kandungan menua) dan merawat kelahiran bayi. Tetapi, sejak adanya bidan desa, peran dukun bayi (sebagian warga) menggantinya dengan peran bidan desa. Peran bidan inilah yang mengubah cara mengkhitan dukun bayi (memotong klitoris meski sedikit, berdarah, dinetralisasi dengan kunyit) dengan membersihkan klitoris saja, tidak memotong yang lebih mengedepankan tindakan medis.

\section{Meminta Doa pada Sesepuh Desa}

Kawasan K auman M enara K ota K udus merupakan wilayah yang memiliki kekhasan yakni memiliki penghormatan ekstra pada kiai desa. Untuk wilayah ini, masih tertradisi orangtua sebelum mengkhitan anak perempuannya datang pada sesepuh desa untuk minta doa kesel amatan khitan. Pada saat acara, diadakan acara berjanjen (membaca salawat $\mathrm{N}$ abi) ol eh muda atau mudi warga setempat yang tergabung dalam perkumpulan kampung, rasulan yakni slametan bubur warna merah-putih (abang-putih), memotong sebagian rambut bayi, dan saudara serta tetangga mele-an yakni forum interaksi antartetangga yang menghadiri acara (jagong) hingga dini hari. Hanya saja, tidak mengundang tetangga untuk bertamu tetapi tetangga/saudara hadir karena kesadarannya ikut berbahagia atas kelahiran bayi familinya/tetangganya. 


\section{Dari Dukun Bayi ke Bidan Desa}

Kesadaran warga dalam mengikuti dinamika kehidupan memengaruhi pola pikirnya. Keberadaan bidan desa sangat mempengaruhi perubahan pola pikir masyarakat, semula khitan anak perempuan dilakukan oleh dukun bayi dialihkan pada bidan desa. Perubahan ini, peran dukun bayi masih difungsikan sebagai tukang pijat ibu yang mengandung (menjelang persalinan) dan memijat bayi. A da pula warga yang masih mempertahankan peran dukun bayi sebagai pengkhitan karena terbatasnya jumlah bidan desa di setiap desa. Di sisi lain, keluarga muda yang masih dipengaruhi oleh pemikiran keluarga seniornya yang selama ini memanfaatkan jasa dukun bayi.

\section{E. PEMAHAMAN DASAR SECARA MEDIS HUKUM MENGKHITAN ANAK PEREMPUAN}

M enyikapi dinamika sosial terkait mengkhitan anak perempuan, $M$ enteri K esehatan RI menerbitkan Peraturan M enteri Kesehatan N omor 1636/ M enkes/Per/X II/2010 tanggal 15 N ovember 2010 tentang Sunat Perempuan. $\mathrm{H}$ al yang dijadikan bahan pertimbangan diterbitkannya Permenkes (1) memberi perlindungan pada perempuan dalam mengkhitannya dengan ketentuan agama, standar pelayanan, dan standar profesi agar terwujud pelaksanaan khitan perempuan secara aman. Pasal 2 (1) dilakukan oleh tenaga kesehatan tertentu, (2) tenaga kesehatan tersebut adalah dokter, bidan, dan perawat yang memiliki surat izin praktik atau izin kerja, (3) tenaga kesehatan tersebut diutamakan yang berjenis kelamin perempuan. Pasal 3 (1) mengkhitan atas permintaan dan persetujuan perempuan yang disunat, orangtua, dan/atau walinya, (2) poin 1 harus diinformasikan kemungkinan terjadi pendarahan, infeksi, dan rasa nyeri. Pasal 4 (1) pelaksanaannya dipersyaratkan di ruang yang bersih, tempat tidur/meja tindakan yang bersih, alat yang steril, pencahayaan yang cukup, dan ada air bersi h yang mengalir, (2) prosedur tindakan medisnya antara lain menggores kulit yang menutupi bagian depan klitoris (frenulum klitoris) dengan ujung jarum steril sekali pakai dengan ukuran 20 G s.d 22 G dari sisi mukosa ke arah kulit tanpa melukai klitoris. Pasal 5 (1) tidak dapat dilakukan pada perempuan (a) yang sedang terinfeksi genitalnya, (b) mengkauterisasi klitoris, memotong atau merusak klitoris, (c) memotong atau merusak labia minora. L abia majora, hymen atau selaput dara dan vagina sebagian atau seluruhnya. Pasal 6 pengkhitan mencatat rekam medis. Pasal 7 
(1) K epala Dinas Provinsi dan K abupaten/K ota membina dan mengawasinya dengan melibatkan organisasi profesi.

M ajelis U lama Indonesia ( $M$ UI) yang diketuai K.H Ma' ruf A min (kini menjadi Wapres) menolak upaya pelarangan khitan perempuan oleh pihak mana pun dengan alasan merupakan ajaran I slam yang pelaksanaannya sebagai hak asasi manusia yang dilindungi oleh UUD 1945. Tatacaranya hanya menghilangkan selaput yang menutupi klitoris, Islam melarangnya bila dilakukan berlebihan. M UI tidak mewajibkan tetapi menolak larangan khitan pada perempuan. B agi M UI, khitan pada perempuan merupakan makrumah (ibadah yang dianjurkan). Wakil Sekjen M UI A mirsyah Tambunan mengatakan Peraturan M enteri K esehatan N omor 1636/M enkes/Per/X II/2010 tanggal 15 N ovember 2010 tentang Sunat Perempuan sesuai amanat UUD 1945, Fatwa MUI, dan aspirasi umat Islam. Dengan demikian, ormas Islam mendukung Permenkes tersebut dan meminta pemerintah untuk tidak merespon upaya berbagai pihak yang ingin melarang khitan perempuan. MUI mengharap Permenkes disosial isasikan ol eh pemda dan organisasi profesi (Kompas.com, Senin 21 Januari 2013).

Pada faktanya, Permenkes N omor 1636/M enkes/Per/X II/2010 berdasarkan hasil evaluasi K ementerian K esehatan bahwa mengkhitan anak perempuan bukan kategori indikasi medis dan belum terbukti bermanfaat bagi kesehatan. D engan demikian, M enteri K esehatan menerbitkan Peratura M enteri Kesehatan Nomor 6 Tahun 2014 tanggal 6 Februari 2014 tentang Pencabutan Peraturan M enkes Nomor 1636/M enkes/Per/X II/2010. Pasal 1 dengan Permenkes N omor 6 Tahun 2014 maka Permenkes N omor 1636/M enkes/Per/ X II/2010 dicabut/tidak berlaku. Pasal 2 M enkes memberi mandat pada $M$ ajelis Pertimbangan $\mathrm{K}$ esehatan agar menerbitkan pedoman penyelenggaraan sunat perempuan yang menjamin kesel amatan dan kesehatan dengan tidak melakukan mutilasi al at kelamin perempuan (female genital mutilation). Permenkes N omor 6 Tahun 2014 tertuang dalam berita negara tahun 2014 Nomor 185 maknanya, muatan Permenkes untuk dipahami publik. Problemnya, Permenkes ini belum dipahami publik secara luas. Dengan demikian, pejabat pemda harus memberi tugas pada dinas kesehatan bersama tokoh masyarakat, tokoh agama, dan pihak terkait menyosialisasikannya agar dipahami publik sebagai pedoman. 


\section{F. SIMPULAN}

A kar pokok persoalan polemik khitan pada anak perempuan (penulis tidak menjumpai perempuan muda atau tua dikhitan) akibat landasan hukum/ fikih mengkhitan perempuan yang diperdebatkan. A nalisis Sayyid Sabiq bahwa semua hadis yang berkaitan dengan sunat pada perempuan tidak otentik (tidak sahih). Permenkes N omor 6 Tahun 2014 tentang Pencabutan Peraturan M enkes N omor 1636/M enkes/Per/X II/2010 mengamanatkan bahwa mengkhitan anak perempuan bukan kategori indikasi medis dan belum terbukti bermanfaat bagi kesehatan. Dengan demikian, perempuan tidak perlu dikhitan. Hanya saja, keberadaan kuantitas dan kualitas bidan di setiap desa yang melayani persalinan secara profesional sangat mempengaruhi perubahan pola pikir warga. Profesionalnya bidan desa dapat mengubah pelayanan persalinan dari dukun bayi dialihkan pada bidan desa. Kondisi ini, pemerintah desa harus responsif dengan (1) memanfaatkan anggaran dana desa (ADD) untuk sosialisasi pentingnya persal inan oleh bidan desa, (2) tunjangan kesejahteraan pada bidan desa yang melayani persalinan warga yang prasejahtera, (3) pendampingan oleh bidan desa bagi ibu muda sejak mengandung usia kandungan muda, dan (4) inventarisasi mobil ambulance untuk melayani ibu hamil dan lainnya, terutama di pedesaan yang jauh dari puskesmas atau rumah sakit. Selama ini, anggaran dana desa belum dimanfaatkan untuk keempat poin di atas.

\section{DAFTAR PUSTAKA}

A I-M arshafi, Saad. 1996. K hitan. Gema Insani Press: Jakarta.

Djauzi, Samsulridjal. 2016. "K hitan yang A man”. Kompas, 19 M aret 2016. A inol. 2013. "K hitan bagi Perempuan Studi hadis dalam Sunan A bu Dawud Nomor Indeks 5271". Humanistika Jurnal Pendidikan dan Hukum Islam Vol. 8, No. 2, Juli. Sekolah Tinggi A gama Islam Zainul Hasan Genggong Kraksaan Probolinggo.

Gunadi, Tuti A stiyah. 2003. "K hitan pada Bayi Perempuan Sangat Berbahaya". Kompas, 24 M aret 2003.

R osyid, M oh. 2008. "Perspektif M asyarakat Pantura terhadap K hitan Perempuan". Palastren Jurnal Studi J ender STAIN Kudus.

Sabiq, Sayyid. 1995. Fikih Sunah Jilid 1. Al-M a'arif: B andung. 
Waharjani. 2000. "K hitan dalam Tradisi Jawa Tinjauan A ntropologisSosiologis". Jurnal Profetika Program M agister Studi Islam U niversitas M uhamadiyah Surakarta.

Wijayati, M ufliha. 2009. "K hitan Perempuan: Syariat atau Tradisi ? M erunut A kar Geneologis Pensyariatan K hitan Perempuan". Jurnal Istinbath Jurusan Syariah STAIN J urai Siwo M etro Vol 6, Nomor 2 November. Zakiyah, Lily. 2006. "Sunat dan Pelanggaran Hak", Kompas, 16 Oktober 2006. 